\title{
Is the Term Spread Still Speaking to Policymakers? Some International Evidence
}

\author{
Massimo Guidolin and Allison K. Rodean
}

$\mathbf{L}$ ong-term interest rates are usually higher than shortterm interest rates; thus, the difference between the two rates, the term spread, is usually positive. Over the past 20 years, for most developed countries, a negative term spread tended to precede a recession approximately three quarters later. ${ }^{1}$ One reason for this predictability might be that the negative term spread results from monetary tightening, a rise in short-term interest rates. These high short rates in turn produce an economic slowdown.

The United States, however, has recently observed a low (sometimes negative) term premium with no recession. For most of 2005 and all of 2006, the average term spread between the yield of 10-year constant-maturity Treasury bonds and of 3 -month Treasury bills was only 35 basis points, compared with its historical average of 142 basis points. Surprisingly, during this time U.S. real GDP maintained 3 percent growth per year. Has the term spread stopped accurately forecasting recessions?

The chart shows the relationship for G7 countries between a negative term spread and real GDP growth three quarters later. If a negative term spread predicted a recession, all the data points would fall in the bottom panel. Clearly this is not the case: Less than one quarter of the points fall in the bottom panel. The predictive power of the term spread has deteriorated even further since the 1990s. By dividing the data into two time frames (i.e., pre- and post-1995), we show that for the data since 1995 (blue squares) a negative term spread has rarely forecasted a recession three quarters in advance. In fact, in the most recent 12 years, a negative term spread has predicted a recession correctly in only one quarter.

The reasons why the forecasting power of the yield curve has deteriorated remain unclear. Some economists have argued that this relationship may depend on the types of shocks affecting the economy (e.g., supply shocks from oil prices vs. demands shocks from increased consumption). ${ }^{2}$ Other economists have argued that globalization has affected the economy in which the Federal Reserve (and, as of late, the European Central Bank) has successfully pursued price-stability goals: It may be that low inflation along with sustained growth can be achieved with weaker and lessfrequent changes in the term spread. In any event, the poor recent predictive power of the term spread lessens the fear that the current low/negative spread in the United States portends a recession in the near future (although it is important to note that the chart shows data for seven countries with rather heterogeneous macroeconomic conditions over the past 50 years). The term spread has simply stopped speaking (i.e., forecasting recessions) to policymakers everywhere around the world.

\footnotetext{
${ }^{1}$ We define recession as two or more consecutive quarters of negative real GDP growth. The G7 countries (discussed below) are Canada, France, Germany, Italy, Japan, the United Kingdom, and the United States.

${ }^{2}$ Smets, Frank and Tsatsaronis, Kostas. "Why Does the Yield Curve Predict Economic Activity? Dissecting the Evidence for Germany and the United States." CEPR Discussion Paper No. 1758, Centre for Economic Policy Research, 1997.
}

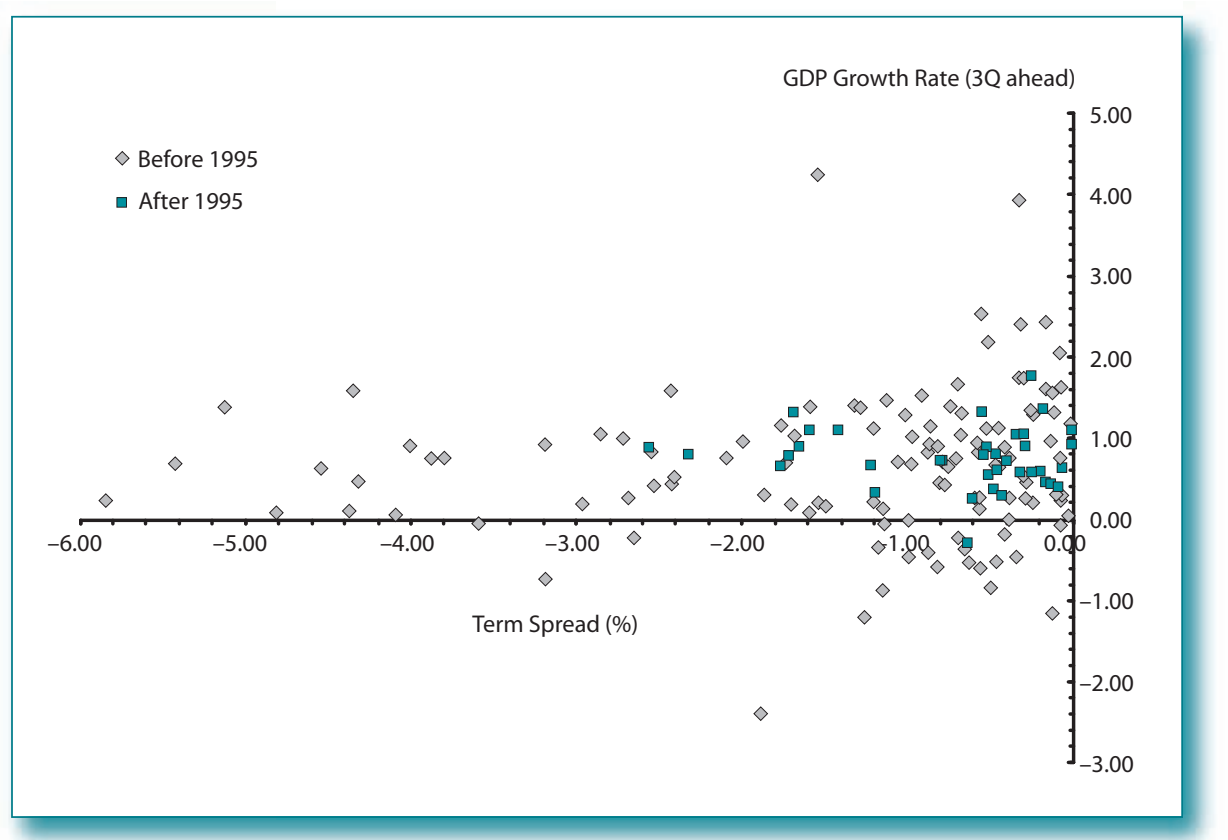

Views expressed do not necessarily reflect official positions of the Federal Reserve System. 